\title{
Computational Fracture Mechanics
}

\section{H. LIEBOWITZ}

School of Engineering and Applied Science, The George Washington University, Washington, D.C. 20052, USA

\section{ABSTRACT}

The field of Computational Fracture Mechanics is reviewed. The paper focuses on the impact of computational methodology on furthering the understanding of fundamental fracture phenomena. The current numerical approaches to the solution of fracture mechanics problems, e.g. finite element methods, finite difference methods and boundary element methods are reviewed. The application of these techniques to the problems of 1 inear elastic fracture problems is discussed. Particular emphasis is placed on three dimensional problems and the issues involved with surface crack geometries and stress intensity factor calculations.

Numerical solutions of two dimensional ductile fracture problems are surveyed. A special focus is placed on the effect of stable crack growth on the field quantities and the implications of numerical solutions for fracture prediction. Creep fracture problems are discussed. The similarities and differences between creep and ductile fracture problems are highlighted. The importance of large strain phenomena and accurate modeling of nonlinear effects are highlighted.

The current state of knowledge of continuum fields for elastostatic cracks, elastodynamic cracks, ductile cracks and viscoplastic cracks is summarized. The range of applicability of asymptotic solutions (especially in the nonl inear regimes) is highlighted.

Major research needs in computational fracture mechanics are detailed. Emphasis is placed on coupled theoretical and numerical approaches. Prospects for future research trends are proffered. Application of fracture mechanics and computational fracture approaches are explored.

\section{KEYWORDS}

Crack propagation; failure prediction; finite element; fracture mechanics; nonl inear methods; numerical methods; research needs. 
INTRODUCTION

The field of fracture mechanics has progressed significantly over the past thirty years. Fracture mechanics nov provides a firm theoretical basis fo the prediction of fracture and the fracture-proof design of new structures for many applications (most notably for applications with solely elastic response). For other problems (where ductility or environmental effects are present), fracture mechanics has progressed toward an understanding and theoretical framework for the future. While much additional research is required before fracture mechanics can be considered a mature discipline, it is recognized that significant adrancement has been made. Fracture mechanics is based on the assumption of a continuum material behavior of the structural component under analysis. The effect of atomic spacing and material microstructure, therefore, is assumed to be totally represented by the constitutive equations employed in the continuum model. Hence, this assumption is the major limiting factor in the development of a quantitative, cohesive theory of fracture. The ultimate theory of fracture should at tempt to couple the microscopic and macroscopic fracture characteristics in a coherent manner. This task is a major requirement of future research in fracture mechanics.

The advent of the digital computer made it possible to solve engineering and scientific problems by using numerical techniques. Many problems which could not be addressed analytically could (at least in theory) be solved numerically. As computers have becone faster, cheaper, more powerful and more widely available, the number of problems which are addressed numerically has grown exponentially. The field of fracture mechanics has benefited dramatically from the use of the digital computer. Routine use of Linear Elastic Fracture Mechanics (LEFM) in fracture-proof design can be largely attributed to the ability to solve fracture problems routinely using digital computers. Critical technology problems involving material and geometric nonlinearities have been addressed successfully using numerical solutions. Indeed, many application areas would have been significantly hindered (if not stopped) without the numerical solution of fracture problems. In addition, muci fundamental understanding of the behavior of materials containing cracks has been gained through numerical simulation of fracture problems.

The purpose of this paper is to provide a critical examination of the impact of numerical methods on the field of fracture mechanics. For the purposes of this discussion, fracture mechanics problems will be subdivided into three major classes: Linear Elastic Fracture Mechanics (LEFM) problems (both static and dynamic), problems involving composite materials, an ductile fracture problems (including rate dependent problems). These broad topics represent the major areas of challenge and application of the field of fracture mechanics.

The paper starts with a discussion of the major numerical approaches available for the numerical solution of boundary value problems. Emphas is is placed on the Boundary Integral Equation Method (BIEM) and the Finite Element Method (FEM). These approacies are the major methods employed for the solution of fracture mechanics problems. Historical note is made concerning integral equation methods and finite difference methods. Emphasis in this section is on the strengths, weaknesses and successes of the methods to date.

The problem areas of LEFM and ductile fracture problems are then considered in turn. The of numerical solutions on the understanding of each problem area and the application of the methodology to design considerations. Also considered is the role of asymptotic and analytic ideal problem solutions in the numerical solution of real engineering problems. An important issue is the value of numerical solutions and the delineation of their limitations.

After surveying the major problem areas and their state of the art, the discussion turns to the major needs of fracture mechanics and the role that numerical methods can play in fulfilling these needs. The majority of this centers on the role of computer simulation, visualization and the interpretation of results. Emphasis is on coupling accurate numerical solutions t physical insight and understanding. A very important concern is the consideration of the numerical solution needs in the formulation stage.

The paper concludes with a discussion of the major obstacles and challenges that face researchers in the numerical solution of fracture mechanics problems. Coupling of numerical and theoretical advances and approaches is emphasized. An attempt is made to focus on those issues which can shed important light on the open questions in the field of fracture mechanics.

\section{NUMERICAL METHODS FOR SOLUTION OF FRACTURE PROBLEMS}

The problems of fracture mechanics reduce to the solution of boundary value problems (which may be static or dynamic) which have mixed boundary conditions. These mixed boundary conditions can give rise to singularities in the stress and strain fields. The problems may involve both material and geometric nonlinearities which complicate the formulation and render prediction of convergence extremely difficult. Because little can be done with these problems analytically, numerical methodologies are required. The advent of large scale computers coupled with the rapid growth in the field of algorithmic methods render many of the problems of fracture mechanics tractable today.

The finite difference method is the oldest technique for the solution of boundary value problems and was widely employed in the 1960s. The method directly involves the solution of the governing differential system in an approximate manner by subdividing the domain of interest into a connected series of discrete points called nodes. These nodes are the sampling points for the solution and are linked using the finite difference poperators to the governing equations. For example, the second order finite operators to the governing equations. field variable is given by

$$
\left.\frac{\partial^{2} \psi}{\partial x^{2}}\right|_{x_{i}, y_{j}}=\frac{\psi\left(x_{i+1}, y_{j}\right)-2 \psi\left(x_{i}, y_{i}\right)+\psi\left(x_{i-1}, y_{j}\right)}{(\Delta x)^{2}}
$$

where $\psi$ is the field variable and $\mathbf{x}$ and $\mathrm{y}$ are the independent spatial variables. This is a second order difference operator and the error is proportional to the square of the mesh spacing in $x\left(0\left(\Delta x^{2}\right)\right)$.

Employment of the finite difference operators results in a system of al abraic equations for the discrete nodal values of the field variable. 
Gradients can be evaluated by employing finite difference operators to the discrete solution.

Finite difference methods can be used to discretize both space and time. In addition, they provide easy error estimation techniques. Unfortunately, finite difference methods are difficult to use for irregularly shaped domains. Often absurd discretization is required for accurate solution. In addition, it is difficult to implement meshes without equal grid spacing. Convergence is difficult to gauge with this characteristic. An excellent discussion of the finite difference approach to the solution of partial differential equations can be found in Lapidus and Pinder (1982).

Finite difference methods have not performed very well for problems involving singularities. One major reason for this is that the fine meshing required near a singularity cannot easily be reduced for the rest of the domain. Special finite difference techniques which directly handle singularities can be developed; however, they have not been very successfu for practical applications. Computational requirements for convergence ar larger than for finite element and boundary element solutions. The finite difference method is not seriously employed for fracture problems today.

In addition to finite difference methods, integral equation methods are a historic approach to the solution of fracture problems and are still used by some researchers today. The basic approach employed involves an analytic formulation of the elasticity problem to the point of a singular integral equation. The singularity is then extracted and the result is a nonsingular integral equation which can be solved quite accurately with any number of techniques. This approach yields excellent solutions, however, it requires an extensive analytic formulation which is different for each new problem. The method is quite useful, nonetheless, for establishing benchmark solutions to compare with other methods as the degree of accuracy can be guaranteed. The method is only applicable to elasticity problems (no nonlinearities). For three dimensional problems, it is almost impossible to derive the integral equations in a finite period of time. An excellent discussion of the method can be found in Muskhelishvili (1953).

Two major numerical approaches are available for the solution of fracture mechanics problems today: the Boundary Integral Equation Method (BIEM) and the Finite Element Method (FEM). These techniques have been widely researched and developed. For two dimensional Linear Elastic Fracture Mechanics (LEFM) problems, either can be employed with much confidence and accuracy. Both BIEM and FEM are actually a class of approaches with many variants which allow a flexible approach for modeling many areas of application. The discussion of each given below will focus on the methods as they commonly are applied to fracture mechanics problems and the variants employed by some authors for better solution characteristics.

The BIEM method is a numerical approach to the solution of linear boundary value problems with known Green's function solutions. The boundary of the domain of interest is discretized using "elements" which are interconnected at discrete points called nodes. For a three dimensional problem, the mesh is two dimensional; for two dimensional problems, the mesh is one dimensional. The boundary value problem is formulated as an equivalent surface or line integral using the Green's function solution and the governing differential system. For linear elasticity in two dimensions, the formulation is based on Betti's theorem and the resulting system equations is given by

$$
C_{1 k} u_{k}+\int_{\Gamma} u_{k} T_{1 k} d \Gamma=\int_{\Gamma} t_{k} U_{1 k} d \Gamma
$$

$(1, \mathrm{k}=1,2)$ where $u_{k}$ and $t_{k}$ are the surface displacement and traction vectors,
is the domain boundary, and $U_{1 k}$ and $T_{1 k}$ are related to the Green's is the dom function solutions for $t$ is specified and the other variable is unknown. These relate to the orysical specified and the other variable is unknows approach can be found in Banerjee and Butterfield (1981). The BIEM method is a quickly convergent, highly robust method for the employ and general purpose commercial software can be developed around the method (the BEASY code is a widely available example; see BEASY in References). Because the surface of the domain need only be discretized, For static problems, the BIEM method reduces to the solution of a system of dense 1 inear equations which may be nonsymmetric (although methods of symmeterizing the systems recently have been very successful). If surface data is the only quantity required (as is the case in many fracture factors and the compliance), the BIEM is often computationally superior to the FEM for two dimensional problems. If interior data is required, the method is computationally costly. For three dimensional problems, BIEM method is computationally costly. For three dimensional problems, B solutions are often very expensive as the resulting linear system is dense,
unbanded and often nonsymmetric. Ongoing research, however, is addressing unbanded and often nonsymmetric. Ongoing research, however, is addressing field quantities and their gradients (e.g. displacements and strains). field quantities and their gradients (e.g. displacements and strains). better gradients within the BIEM concept.

For applications in fracture mechanics, the BIEM has received a good bit of attention recently. For two dimensional problems, the BIEM can be employed attention recently. For two dimensional problems, the BIEM can be employed for the solution of fracture problems with much success. Mesh generation is quite simple and users can master the techniques rapidy (much more so than for the FEM). Accurate solutions can be obtained and reasonable error estimates can be predicted. It is certainly competitive with the for fracture mechanics problems are summarized in Table 1.

Three dimensional LEFM problems have been solved using the BIEM without great success. These solutions are quite costly and of ten do not produce good solutions. As an example, consider the problem of an edge cracked rectangular bar subjected to uniaxial uniform tensile stress as shown in Fig. 1. The resulting stress intensity factor distribution is shown in Fig. 2 and is compared with well established finite element results. It can be seen that near the midplane the results agree well. Far from the midplane, however, resolution degrades. Because it is well known that FEM solutions of surface crack problems overestimate the boundary layer effect near the free surface, the BIEM results are in error (Rooke et al., 1987). Interior crack problems have been solved successfully; however, this is not a sufficient test of the method. Ongoing research hopefully will address this problem, although the BIEM is not a current competitor for three dimensional problems. 
Table 1. Numerical methods for the solution of fracture problems

Method

Strengths

Weaknesses

Finite

Easy to employ

Error estimates available

Slow convergence

Uniform mesh requirements

Cannot model singularities

\begin{tabular}{lll}
\hline $\begin{array}{l}\text { Finite } \\
\text { Elements }\end{array}$ & $\begin{array}{l}\text { Good convergence } \\
\text { Singularities can be } \\
\text { modeled }\end{array}$ & $\begin{array}{l}\text { Modeling is difficult } \\
\text { Few exiting error } \\
\text { estimators }\end{array}$ \\
\hline $\begin{array}{l}\text { Boundary } \\
\text { Elements }\end{array}$ & $\begin{array}{l}\text { Modeling is easier } \\
\text { Error estimation } \\
\text { is easier }\end{array}$ & $\begin{array}{l}\text { Computationally more } \\
\text { expensive for most } \\
\text { problems } \\
\text { Converge slowly for } \\
\text { singular problems }\end{array}$ \\
$\begin{array}{l}\text { Hybrid } \\
\text { Approaches }\end{array}$ & $\begin{array}{l}\text { Good for specific } \\
\text { problems }\end{array}$ & $\begin{array}{l}\text { Usually developed for } \\
\text { restricted problem class }\end{array}$ \\
& $\begin{array}{l}\text { Generally very } \\
\text { accurate }\end{array}$ & $\begin{array}{l}\text { often difficult to } \\
\text { implement }\end{array}$ \\
\hline
\end{tabular}

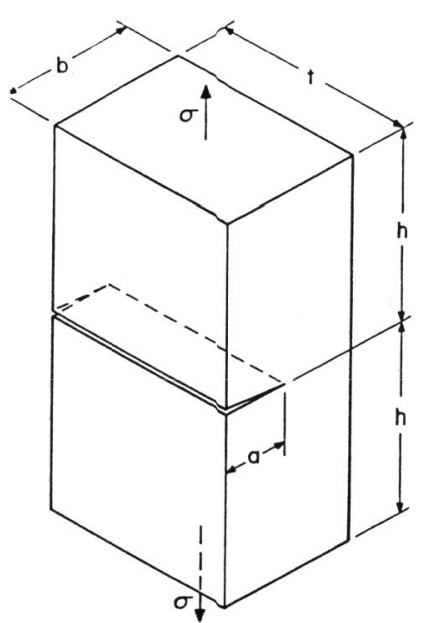

Fig. 1 Edge cracked rectangular bar subjected to enarial uniform

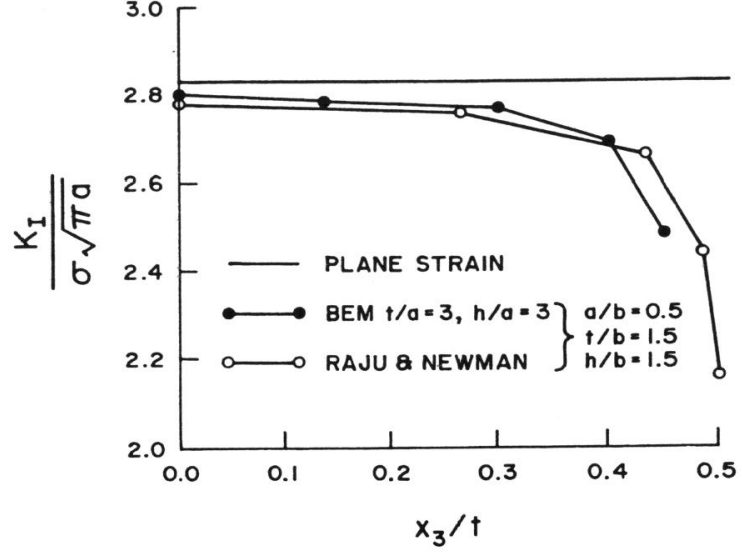

Fig. 2. Variation of the stress intensity factor along the crack front

Much effort has been focused recently on the extension of BIEM to nonlinear problems where known Green's functions do not exist. This work is in its infancy and it is fair to say that the approach has yet to impact the field of fracture mechanics. Indeed, available solutions to problems with extensive nonlinear material behavior are disappointing (e.g. Wilson et a1., 1985) Ongoing research may establish BIEM approaches to nonl inear problems which produce reasonable answers. For nonlinear problems, analytical Green's functions are not available. A variational approach with assumed trial and weight functions must be employed. The formulation

formulation as the FEM.

The FEM is the most widely employed numerical method for the solution of fracture mechanics problems. The formulation of the FEM is based on a variational statement of the governing physics. For the problems of linear elasticity, the principle of Virtual Work, given by

$$
\int_{V} \sigma_{i j} \delta \varepsilon_{i j} d V=\int_{S} \sigma_{i j} n_{j} \delta u_{i} d S
$$

is employed where $\sigma_{i j}$ is the stress tensor, $\delta \varepsilon_{i j}$ is the virtual strain tensor due to virtual displacements $\delta u_{i}$ and $n_{j}$ is the normal vector to the surface of applied tractions. The domain is discretized into subdomains (elements) which are interconnected through common discrete points (nodes). The primary unknown field variables are nodal values. The formulation reduces the problem to the solution of a system of algebraic is a ions in terms of the nodal variables (for dynamic problems, the result is a system of ordinary differential equations). Finite ele tend to be relatively banded and symmetric for most problems. The nonlinear problems, algorithms are also available, however, accuracy and convergence are much larger problems. 
For fracture mechanics problems, the finite element method can be employed in the standard manner or modified to account for the singular nature of the near crack fields. A summary of these methods can be found in Liebowitz and Moyer (1987), and they are treated in this paper with specific application areas. As discussed in the next section, calculation of two dimensional stress intensity factors for LEFM problems is commonplace and can be performed using commercial software by the average user (any commercial code containing a quadratic displacement element, e.g. MARC, ABAQUS, NASTRAN, ADINA can be employed). Indeed, this application is the most successful example of the use of LEFM and FEM in design. For section discusses these issues in nore detail.

A major problem with the finite element method is the design of an appropriate mesh. While much experience has been gained in the past twenty years, finite element mesh design (especially in three dimensions) is more of an art than a science. Automated mesh design is still an emerging discipline and all known algorithms produce unrealistic meshes for problems containing cracks. Another major problem with the finite element method is the prediction of error. This is an area where promising research is ongoing, however, the current state of the art is not very accurate.

The FEM has been widely employed for the solution of nonlinear fracture problems. Problems involving ductile crack growth, creep crack growth, fatigue and large deformation can be addressed accurately using the F often, however, these calculations are extremely time consuming and expensive [for example, a modest anount of creep crack growth was modeled by Moyer and Liebowitz (1987) and required 75 CPU hours of VAX 11-780 time to reach a converged solution]. Understanding the results and establishin converged solutions in the nonlinear regime is also more of an art than science. While much research is needed and ongoing, the Fen is a useful numerical tool for addressing nonlinear fracture problems.

of all the numerical approaches available, the FEM is the most widely employed and understood method for the solution of fracture mechanics problems. While the method continually evolves, the current state of the art is sufficient to address many important problems. Much understandin of fracture phenomena has arisen from numerical solutions of fracture problems. The remainder of this paper examines the key areas in fracture mechanics and highlights the impact of numerical methods (especially the FEM) on the field of fracture mechanics.

IMPACT ON LEFM

The ability to predict accurately the stress intensity factors for cracked elastostatic bodies using standard numerical techniques has greatly advanced the use of Linear Elastic Fracture Mechanics concepts in application. Both BIEM and FEM technologies have been developed for the prediction of stress intensity factors for cracked bodies of arbitrary geometry and loading. In two dimensions, this is a mature technology which can be routinely employed. Most commercial FEM and BIEM codes have 2-D elastostatic fracture capabilities built-in and automated. A minimal amount of user knowledge is required.

The Griffith energy release rate theory of LEFM is widely accepted as a design criteria for fracture proof design. The application of this theory reduces to determining the largest possible flaw in a design which can exist in a subcritical state. If this flaw size is larger than an acceptable flaw size, then the design is considered safe assuming that only elastic deformation is present. The flaw size is determined by assuming the existence of a flaw at a location of stress concentration and calculating the energy release rate associated with a virtual extension of that flaw. In practice, it is not necessary to calculate the energy release rate as this can be related to the stress intensity factor of the crack. It is sufficient, therefore, to obtain accurate numerical stress intensity factors for arbitrary geometries and loadings.

The Griffith approach to fracture proof design is, unfortunately, inadequate for many applications. Real structures and components develop cracks which are three dimensional in geometry and which are not subjected solely to tensile opening. The Griffith criteria requires that the crack can be idealized as a two dimensional line of discontinuity and that the remote loading is tensile and normal to the crack line. It is necessary, therefore, to look beyond the Griffith criteria for many applications.

often, anticipated cracks in components and structures form due to a stress concentration near a free surface. This phenomenon gives rise to surface cracks which cause many real world failures. In many cases, it is acceptable to assume that cracks which will form are subjected to pure tensile opening but cannot be idealized to a two dimensional line crack. In this situation, the stress intensity factor along the crack front can be used as a design criterion with acceptable safety for interior cracks. The problem, therefore, reduces to finding the distribution of stress intensity along a three dimensional crack front where the crack is subjected to pure tensile loading.

The prediction of three dimensional stress intensity factor distributions is not a straightforward process. Research in this area has been ongoing for almost ten years in earnest (some work was performed prior to the lat 1970 s, however, due to the limited computer resources available, the results were not accurate). FEM approaches are basically extensions of the two dimensional technology presented previously. Special singular elements have been proposed by Tracey (1973), Blackburn and Hellen (1979), Hilton (1977) and others. These singular elements are based on employment of the asymptotic displacement field in the finite element formulation directly. The element geometry is the same as the corresponding standard elements (usually either tetrahedrons or triangular prism elements as shown in Fig. 3). As analyzed elsewhere (Liebowitz and Moyer, 1987; Moyer, 1988), these approaches require the assumption of a local state of plane strain near the crack front which has not been establ ished analytically. They must be utilized, therefore, with discretion.

As a desirable alternative to special finite elements, Henshell and Shaw (1975) and Barsoum (1976) noticed that distortion of the placement of midside nodes in higher order isoparametric elements leads to a singular strain in the element. The fifteen node prism with quarter point nodal displacement is shown in Fig. 4. While many singular fields are attainable, the square root singularity of the sharp crack is obtained when the midside the midside code with minimal user knowledge. The major drawback with the use of 


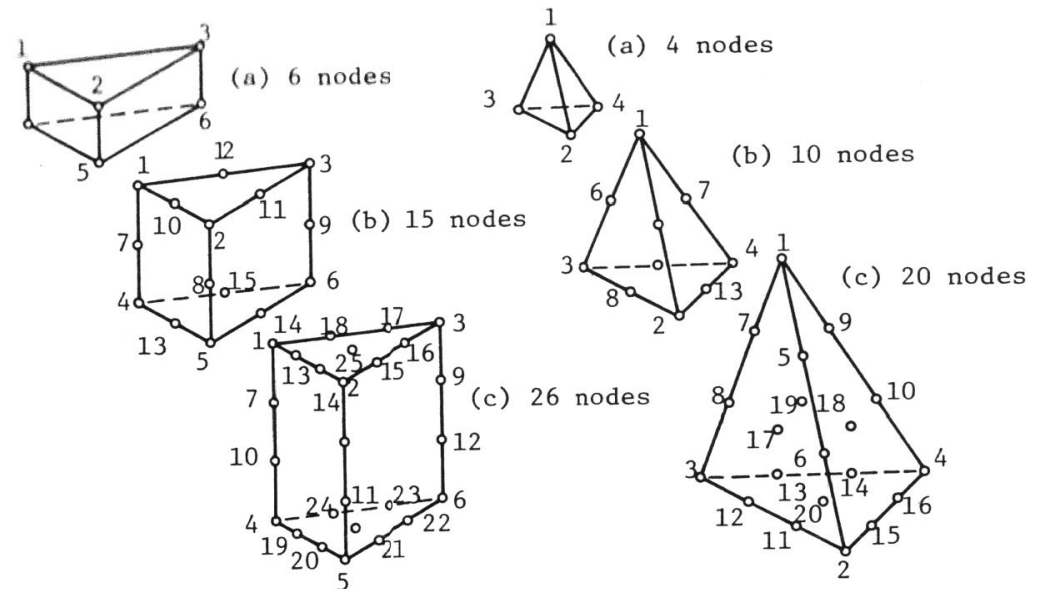

Fig. 3. Typical three dimensional tetrahedral and prism elents

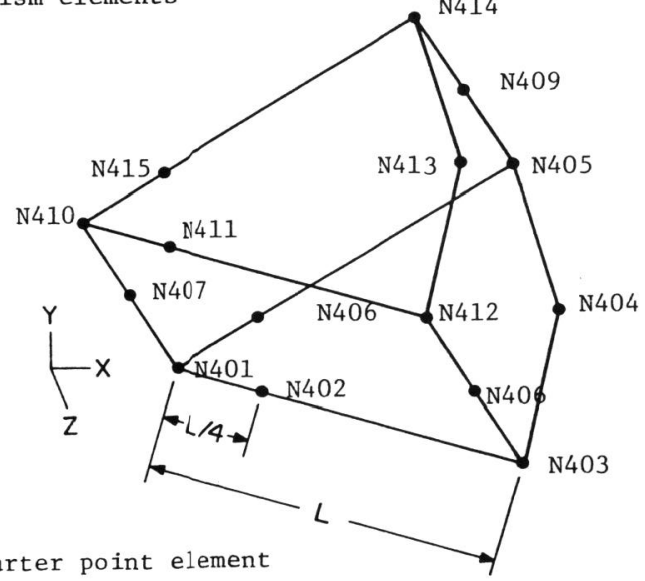

Fig. 4. Quarter point element

quarter point elements is the requirement of post processing the stress intensity factors from the FEM solutions.

Hybrid approaches to the solution of stress intensity factors in three dimensions are discussed extensively in the literature (for example, see the reviews in Liebowitz and Moyer, 1987 and Kuna, 1982). The basic concept behind hybrid elements is that neighboring elements can have different primary unknowns and can have different functional forms (e.g. one element could employ and assume stress distribution while a neighboring element employs an assumed displacement distribution). As suggested by the name, many formulations of hybrid elements can be advanced. hybrid elements are the same as conventional elements. Various authors have employed hybrid elements to solve three dimensional herid problens. Accurate and dependable solutions can be achieved using hybrid elent The complexity of their formulation, however, makes computational addiementation more difficult than wit is not guaranteed even for problems, the use of hybrid elements is restricted to experienced analysts.

As stated previously, it is usually necessary to obtain stress intensity factors from FEM field solutions. After much research over the years, two approaches have emerged: the multi-term displacement field approach and the nodal force approach. The asymptotic displacement field for a

stationary, three dimensional elastic crack assuming a local state of plane strain is given by

$$
\begin{aligned}
& u_{1}^{\ell}=\left(\frac{1+v}{E}\right)\left(\frac{2 r}{\pi}\right)^{\frac{1}{2}}\left\{K_{I} \cos \frac{\theta}{2}\left[(1-2 v)+\sin ^{2} \frac{\theta}{2}\right]+K_{I I} \sin \frac{\theta}{2}\left[2(1-v)+\cos ^{2} \frac{\theta}{2}\right]\right\} \\
& u_{2}^{\ell}=\left(\frac{1+v}{E}\right)\left(\frac{2 r}{\pi}\right)^{\frac{1}{2}}\left\{K_{I} \sin \frac{\theta}{2}\left[2(1-v)-\cos ^{2} \frac{\theta}{2}\right]-K_{I I} \cos \frac{\theta}{2}\left[(1-2 \nu)-\sin ^{2} \frac{\theta}{2}\right]\right\} \\
& u_{3}^{\ell}=2\left(\frac{1+v}{E}\right)\left(\frac{2 r}{\pi}\right){ }^{\frac{1}{2}} K_{I I I} \sin \frac{\theta}{2} .
\end{aligned}
$$

The local coordinate system is defined in Fig. 5. The multi-term displacement approach is the result of many years of numerical experimentation with various asymptotic displacement formulations. The method currently employed was formulated by Ingraffea (1980) and has many followers. The multi-term displacement formulation employs the asymptotic displacement $f$ ield together with some higher order terms. Accurate predictions are obtained if a local state of plane strain exists near the point of stress intensity factor evaluation.
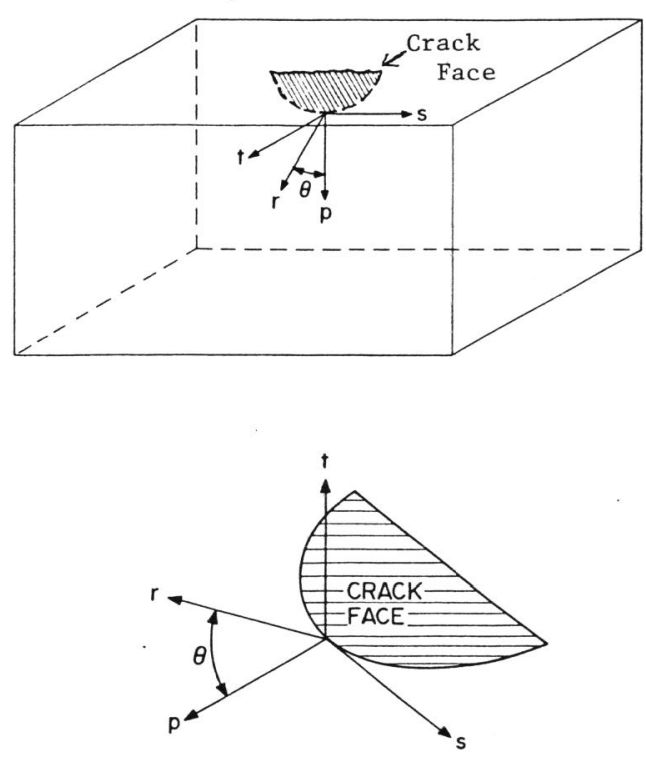

Fig. 5. Three-dimensional crack geometry 
The alternative method is the noddl force approach. This approach was proposed by Raju and Newman (1977) and is based on integration of the asymptotic stress field given as

$$
\sigma_{i j}=\frac{k_{1}(s)}{\sqrt{r}} f_{i j}(\theta)+\frac{k_{2}(s)}{\sqrt{r}} g_{i j}(\theta)+\frac{k_{3}(s)}{\sqrt{r}} h_{i j}(\theta)
$$

where the functions $f, g$ and $h$ are known. It has been employed to solve a wide variety of tensile opening problems. From a theoretical viewpoint, the nodal force method is more acceptable than the multi-term displacement method. The nodal force approach utilizes the asymptotic stress field instead of the asymptotic displacement field. This approach, therefore, does not require the assumption of plane strain in the neighborhood of the crack front. Due to the assumption displacement method can yield erroneous results where crack front curvatures are large or as the crack front approaches a free surface. Unfortunately, the displacement approach is widely utilized.

An alternative approach to the understanding of LEFM phenomena involves calculation of energy release rates directly without the concern for stress intensity factors. Stress intensity factors can be predicted from the calculated energy release rates. For two dimensional problems, many path independent integrals can be related (with certain a problens, many path direction of crack ad can to factors. The famous $J$ int

$\mathrm{J}$ integral is defined as

$$
J=\int_{r}\left(U-\sigma_{x} \frac{\partial u}{\partial x}-\tau_{x y} \frac{\partial \nu}{\partial x}\right) d y+\int\left(\tau_{x y} \frac{\partial u}{\partial x}+\sigma_{y} \frac{\partial v}{\partial x}\right) d x
$$

where the geometry is as defined in Fig. 6. Although $J$ is the most widely employed path independent integral, which is related to the stress intensity factors, many alternate formulations are available. From a computational standpoint, choice of which path independent integral to employ is made based on ease of computation for the geometry and loading involved. Discussions on this approach for two dimensional problems can found in Dexter (1987) and Liebowitz and Moyer (1987).

Extension of global energy methods to three dimensional problems is difficult, but not impossible. For pure mode I problems, two basic pproaches are available: the virtual crack extension method (VCEM) (Parks, 1974) and the virtual crack Closure technique (VCCT) (Newman, 1988). The VCEM works by calculating the change in stiffness produced by a small amount of crack extension into the near tip material. The VCCT works by calculating the energy required to close the crack by a small amount. Both of these methods produce an estimate of the pointwise energy release rate along a three dimensional crack front. Stress intensity factors can be obtained, therefore, assuming elther plane stress or plane strain. The energy release rate calculation, however, does not require the assumption of plane stress or plane strain. Because the standard LEFM fracture criterion is based on energy release rate and not stress intensity factors, these energy methods may be quite useful for three dimensional opening mode fracture problems. The VCCT method has the computational advantage of only

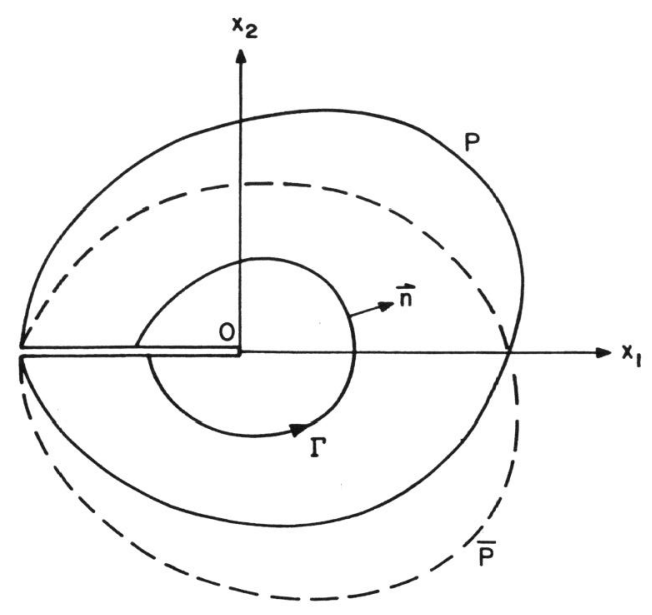

Fig. 6. Geometry for J integral calculation

requiring knowledge of the nodal forces and displacements. The computation is not based on the stress or strain fields from the analysis. The VCCT method can often predict reasonable results without the use of singularity elements.

To demonstrate the capabilities of these techniques, consider the problem of a semi-circular surface crack at the edge of a notch as shown in Fig. 7. This problem recently has been solved using the COD method, the force method and the VCCT (Newman, 1988). The results are shown in Fig. 8 using both singular and nonsingular finite element analyses. While all three methods produce good results, the VCCT results are good even without the employment of singular elements. This is the major advantage of the method.
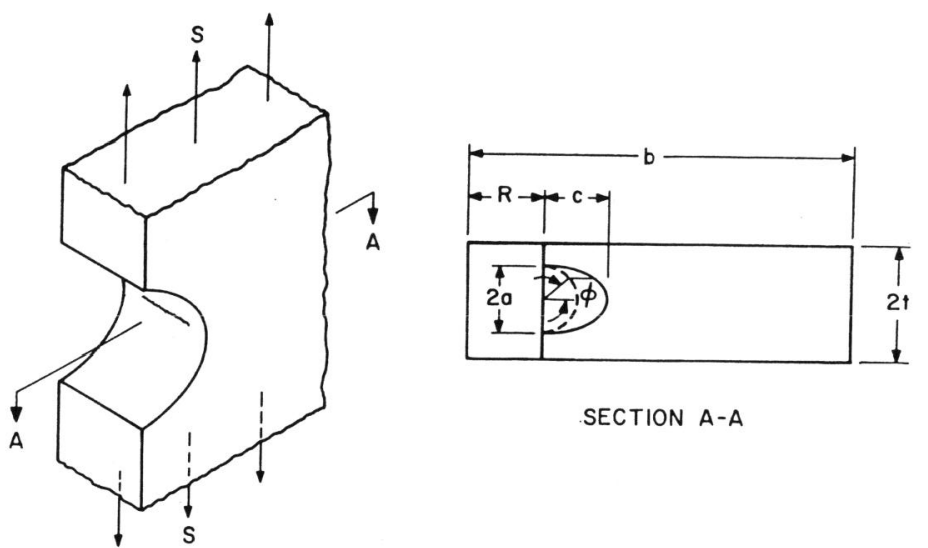

SECTION A-A

Fig. 7. Specimen configuration and loading 

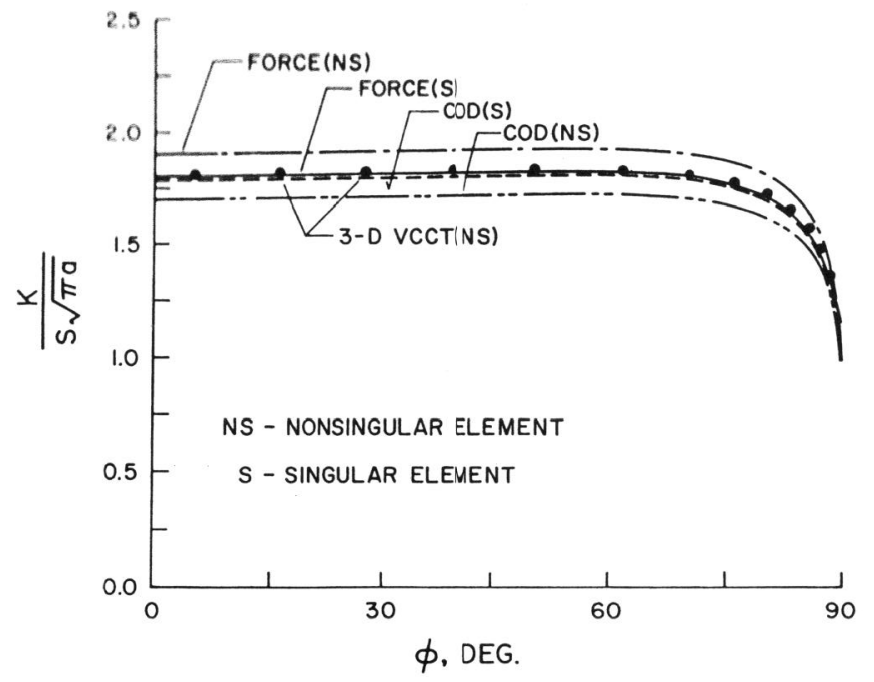

Fig. 8. Comparison of rormalized K calculated from 3-D VCCT, force, and COD methods.

Global energy methods, unfortunately, are not very useful for mixed mode problems. They require knowledge of the direction of incipient crack growth. In general, this information is unavailable. Several mixed mode growth. In general, this information is unavailable. Several mixed mode crack irection criteria exist which could be employed to estimate the direction of crack advance, however, the computational results are quite sensitive to advance direction on the basis of experience with two dimsional problens (Liebowitz ard Moyer, 1987 ) to be very successful.

The BIEM can be employed for the solution of three dimensional crack problems in much the same way as the FEM. Much work in two dimensions demonstrates that the BIEM can produce quite accurate solutions to fracture problems and is computationally competitive with FEM. For three dimensional problems this may not be the case. BIEM methods tend to be quite expensive for three dimensional calculations, of ten much more expensive than the FEM. In addition, studies to date have not resolved the stress intensity distribution detail for the standard three dimensional surface crack problems used as benchmarks in three dimensions. Summary of this work to date can be found in Cruse (1987).

In addition to the study of static LEFM problems, much work has been performed for dynamic LEFM problens. In the dynamic case, two problems are important: that of a running crack and that of a static crack with elastic waves impinging. The problem of stress intensity factor calculation for static cracks in elastic materials subjected to time dependent loading is no more difficult than the corresponding static problem. The same solution methodologies are employed and the results can be calculated to the same accuracy. Computational requirements are greater, however, no new problems arise numerically.

The problem of a running crack in an elastic material is much different from the problem of a static crack. FEM solutions have had a major impact on this area. Few analytic solutions to realistic problems are available (even in two dimensions), therefore, robust numerical approaches are essential. The first realistic solution to the problem of a running crack was presented by Anderson and King (1977). They introduced a nodal release algorithm which models the changing boundary conditions of a growing crack. The method has proved to be very robust and easy to implement -even in commercial finite element codes -- and is widely employed. This algorithm has allowed many researchers to study running crack problems for a wide variety of geometries and loadings. Many examples are available in the literature; a good review is given by Williams and Knauss (1985).

For two dimensional running crack problems, the decision to employ either conventional elements or singular elements is not totally established. Many authors have produced excellent results to difficult problems employing only conventional elements (e.g. Williams and Knauss, 1985). other authors employ singular elements with equal accuracy and claim computational superiority (e.g. Liebowitz and Moyer, 1987). Many examples exist in the literature, however, where one method or the other produce marginal results to seemingly simple problems. These examples demonstrat that the modeling of running cracks require careful study of solution convergence and stability for each new problem. This aspect is probably more important than the choice of element type.

An interesting example of dynamic crack propagation simulation involves the problems of interacting cracks. Consider the problem of two cracks in a sheet which are opened by wedge loads (Swenson and Ingraffea, 1987). The geometry is shown in Fig. 9 where the arrows indicate the wedge loading. The cracks are slightly misaligned to provide initial asymmetry. Figure 10 shows the cracks at three stages of the analysis. Initially, the cracks repel each other and, as propagation continues, they attract. At the final stage, the two cracks intersect. Figure 11 shows the stress intensity factor histories as a function of crack length. The positive mode II component is evident during the avoidance stage and the negative mode II is evident during attraction.

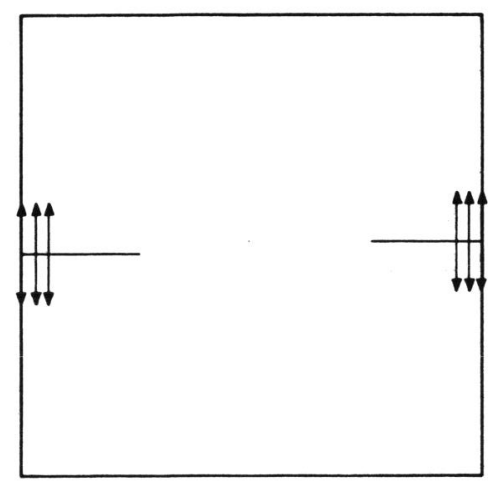

Fig. 9. Geometry of problem 


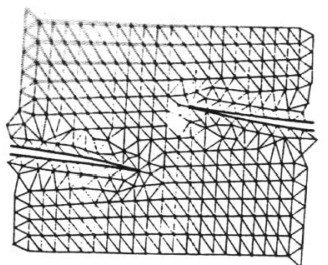

(a) Crack avoidance

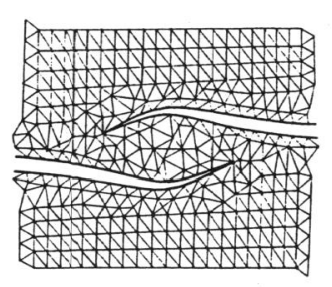

(b) Attraction

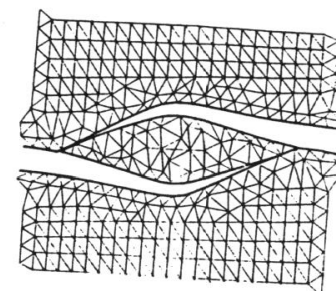

(c) Final separation
Fig. 10. Displacement plots during crack propagation (width of detail 0.25 inches)

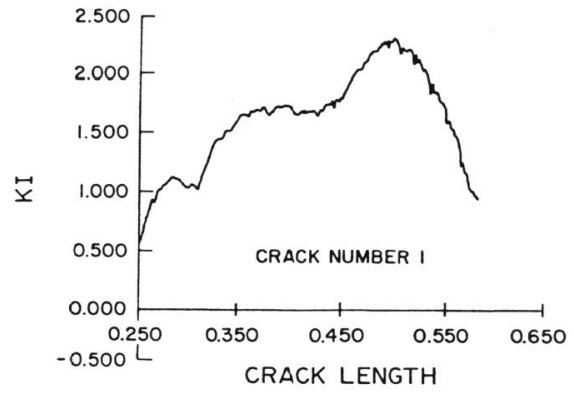

(a) Hode I

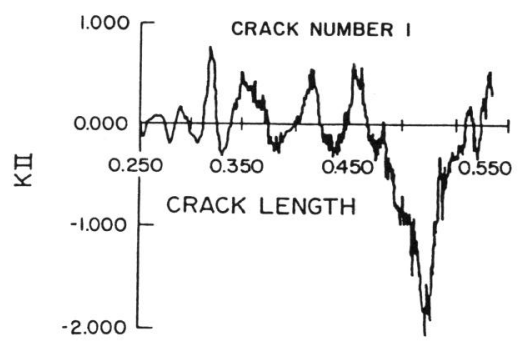

(b) Mode II
Fig. 11. Calculate stress intensity histories

An alternative approach to modeling running cracks involves the use of a moving element. Atluri and others have employed this concept in their moving singular element studies (Atluri and Kathisesan, 1980). They use hybrid element which produces reasorable results. The main problem with the hybrid approach is the complexity of formulation and the difficulty in implementation. In addition, hybric elements tend to behave unpredictably in convergence studies, making their routine employment problematic. Few authors have pursued , making their rout ine employment problematic. authors have pursued this approach. Moving crack tip elements can be ductile crack growth, but not for dynamic fracture. The computational requirements for moving elements, however, appear to be on the same order as for standard approaches with nodal release (Moyer and Liebowitz, 1984).

To date, little work has been done on three dimensional dynamic problems. The few studies in the literature employ numerical modeling too coarse for the obtaining of accurate results. This is mainly due to the prohibitive computational costs for three dimensional dynamic fracture calculations and the lack of experimental data for comparison.

For problems of two dimensional LEFM, the FEM and BIEM technology available today is sufficient for the solution of most problems. The convergence nature and the computational requirements are well established, and routine employment is feasible and, in fact, in place. For three dimensional problems, however, much more research is required before routine analysis can be performed. Specifically, the problem of the intersection of a crack front with a free surface is still an open question. In addition, the (assuming the desired parameter is definable) is still open. Research in this area is needed and discussed in depth in a later section.

\section{PROBLEMS OF DUCTILE FRACTURE}

Numerical methods have probably provided more understanding of the field of ductile fracture mechanics than of any other discipline in the field of fracture. Due to the extreme mathematical complexity of the problems, idealized situations. Often, the physical processes of interest are lost due to simplifications required for the attainment of an analytic

due to simplifications required for the attainment of an analytic approximation. Numerical methods, therefore,
understanding of the basic physical problem.

For the purposes of this discussion, ductile fracture will be divided into four subtopics: elastic-plastic problems without subcritical crack growth, elastic-plastic problems with subcritical crack growth, rate dependent plasticity (or creep) problems without subcritical crack growth, and rate dependent plasticity problems with subcritical crack growth.

The problem of elastic-plastic (rate independent) fracture without prior, subcritical crack growth is the easiest problem to study. An extension of the energy release rate concept to nonlinear elastic materials appears to provide a suitable fracture criterion. Although computation times may be long, two dimensional geometries can be analyzed quite accurately with current FEM technology. This approach can be extended to three dimensional mode I problems through the use of domain integrals. The energy release rate for a stationary crack in a monotonically responding medium can be written as (Shih et al., 1988)

$$
\begin{aligned}
\bar{G}=\int_{V}\left[\sigma_{i j} \frac{\partial u_{i}}{\partial x_{k}} \frac{\partial q_{k}}{\partial x_{j}}-(w+L) \frac{\partial q_{k}}{\partial x_{k}}\right. & +\rho\left(\frac{\partial^{2} u_{i} \partial u_{i}-\partial u_{i} \partial^{2} u_{i}}{\partial t^{2} \partial x_{k} \partial t \partial x_{k} \partial t}\right) q_{k} \\
& \left.+\left(\sigma_{i j} \frac{\partial^{2} u_{i}}{\partial x_{j} \partial x_{k}}-\frac{\partial w}{\partial x_{k}}\right) q_{k}\right] d v
\end{aligned}
$$


where $W$ is the strain energy density, $L$ is the Lagrangian of the system, 4 is the displacement vector and $q_{k}$ is a weight function. This formulation holds for static and cynamic responses. The major limitation is the required assumption of monotonic field response and a stationary crack front. This parameter is useful for characterizing fracture which is not preceded by ductile tearing or any non-monotonic load history.

Unfortunately, many real fracture problems do not satisfy these criteria.

An important problem for the prediction of the early part of fracture life is the study of cracks subjected to mixed mode loading. The problem of ductile crack solutions for mixed mode problems has been addressed numerically by many authors in the past (e.g. Shih, 1974 and Moyer and Haegele, 1988). No mixed mode ductile fracture criteria, however, have been established, therefore, these solutions can only provide insight into field distributions. While this is an important contribution, fundamental work toward a general fracture criteria is needed.

A major problem in extending the current knowledge of ductile fracture is the lack of understanding of the local crack tip (or crack front in three dimensions) fields in the elastic-plastic regime. For two dimensional problems with highly restrictive constitutive relations, an asymptotic analysis has suggested fields in the form

$$
\begin{aligned}
& \sigma_{i j}=\left(\frac{J}{\alpha \varepsilon_{y}{ }_{y} I_{n} r}\right)^{\frac{1}{n+1}} \tilde{\sigma}_{i j}(\theta) \quad u_{i}=\left(\frac{J}{\alpha \varepsilon_{y}{ }_{y} I_{n}}\right)^{\frac{n}{n+1}} \frac{1}{n+1} \tilde{u}_{i}(\theta) \\
& \varepsilon_{i j}=\left(\frac{J}{\alpha \varepsilon_{y}{ }_{y} I_{n} r}\right)^{\frac{n}{n+1}} \tilde{\varepsilon}_{i j}(\theta) .
\end{aligned}
$$

The required assumptions for the derivation of these equations, however, are met only in a negligibly small region near a crack tip. Many numerical studies over the past 15 years have demonstrated that these fields fail to characterize the material response in physically realistic dimensions. A this solution dominates even on the plane strain plane (Parks and Wang, 1988).

To demonstrate the considerable complexity, a recent asymptotic study was undertaken numerically. The near crack tip region was studied by applying an elastic stress field ( $\mathrm{K}$ dominant) to a region far from the plastic stress, strain and energy fields were predict studied. The resulting material. Small strain theory was employed. same assumptions and boundary was employed. This problem employed the The major difference is that the is a log-log plot of the effective stress a is a log-log plot of the effective stress ahead of the crack tip for the transition from elastic-plastic region, the degree of singularity changes abruptiy the transitions for a dis, the degree of singularity changes abrupty, asymins for a distance, and then continually increases toward the alutic transition decreases and approaches the asymptotic for pure mode II. The

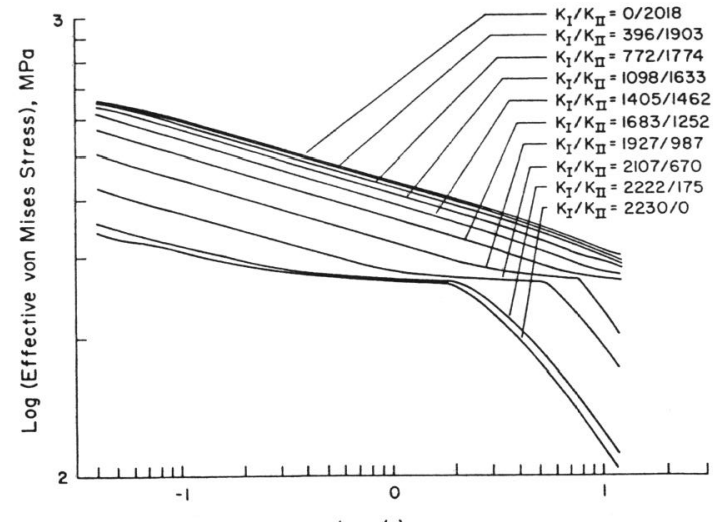

Fig. 12. Full logarithmic representation of effective von Mises stresses along line $\theta=0^{\circ}$ for all of mixed-mode cases considered

assumption of geometrically infinitesimal deformations, however, is violated for mixed mode loading as significant rotation is observed. As is demonstrated in McMeeking (1987), it is critical to assess the influence of finite deformations before an understanding of the near tip stress fields can be obtained.

Most ductile fracture problems exhibit significant stable crack growth prior to final instability. The simplest problem of a mode I crack growing in a plane strain material yields a significant mathematical problem. Analytic attempts at asymptotic solutions produce dubious results at best. This is easily understood as the assumption required to attain the solution restricts its possible validity to a region so small that the assumption of a homogeneous, isotropic continuum must be suspect. For the static crack problem, the HRR field is of ten restricted to a zone which is of the order of the physical process zone (Dean and Hutchinson, 1980). Because asymptotic solutions for growing cracks are restricted to regions (on the average) of between $1 / 5$ and $1 / 10$ of the corresponding HRR region, the solutions are not very useful.

Fortunately, the problem of stable mode I crack growth has been extensively studied numerically over the past ten years. The nodal release algorithm is most frequently employed for the modeling of crack growth. Early investigations yielded qualitative insight into the effect of crack growth and local yielding on field variables relatively far from the crack (e.g. Dean and Hutchinson, 1980, and Hoff et al.1986). These quantities were often "matched" with asymptotic solutions to construct a "full near field" solution. As large-scale computational facilities have increased, however, solution is lared numerical studies have demonstrated that the asymptotic more fields arom from the crack tip to the elastic field (assuming free surface effects do not complicate the phenomena). Fracture criteria based on assumed asymptotic dependencies, thereforer are not criteria to be Read (1988) and to Moyer and Kunze (1988). 


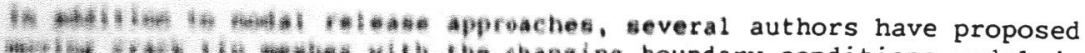

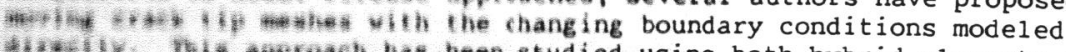
then Mily Mis aprosach has been studied using both hybrid elements and

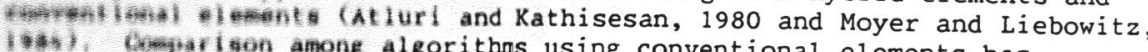
ateminut ated that among algorithns using conventional elements has provide good, convergent solutions to problems of ductilo crack elements Unfortunately the added complich approach yields no significant computational advantaes the moving element comparisons for hybrid elent

Crack growth criteria for the stable tearing regime can be divided into two local crack tipse based on global integral approaches and those based on the early stage of ductile frot rate and that subequet frowth opening angle (Hoff et al constant crack however, they have been insufficienty other criteria have been proposed; their utility. Stable crack growth loyed for the

Table 2. Summary of ductile crack growth theories

\begin{tabular}{|c|c|c|}
\hline Criteria & Type & Comments \\
\hline $\begin{array}{l}\text { Tearing } \\
\text { Modulus }\end{array}$ & Global & $\begin{array}{l}\text { Contrary to experiment for most materials } \\
\text { When applicable, range is extremely limited }\end{array}$ \\
\hline $\begin{array}{l}\text { Crack-tip } \\
\text { Opening } \\
\text { Displacement }\end{array}$ & Local & $\begin{array}{l}\text { Definition is arbitrary } \\
\text { Difficult to measure and verify }\end{array}$ \\
\hline $\begin{array}{l}\text { Crack-tip } \\
\text { Opening } \\
\text { Angle }\end{array}$ & Local & $\begin{array}{l}\text { Difficult to measure and verify } \\
\text { Definition is arbitrary }\end{array}$ \\
\hline $\begin{array}{l}\text { Strain Energy } \\
\text { Density Theory }\end{array}$ & Local & $\begin{array}{l}\text { Untested in application } \\
\text { Material parameters difficult to determine }\end{array}$ \\
\hline $\begin{array}{l}\text { Plastic Energy } \\
\text { Approach }\end{array}$ & Globa1 & Parameters are specimen dependent \\
\hline $\begin{array}{l}\text { Stochastic } \\
\text { Approaches }\end{array}$ & $\begin{array}{l}\text { Usually } \\
\text { local }\end{array}$ & $\begin{array}{l}\text { Parameters are non-physical } \\
\text { Difficult to verify for application }\end{array}$ \\
\hline
\end{tabular}

To evaluate crack growth criteria, numerical simulation of experimental histories are required. Such simulations, however, must employ the raw experimental data as the only input without the bias of the fracture parameter being studied. Few such simulations have been performed to date. A recent study, however, followed these criteria for a common steel material (Moyer and Kunze, 1988). The results indicate that the dJ/da rate is not constant over any reasonable proportion of crack growth in a standard test specimen. The J integral versus the crack extension is plotted in Fig. 13, and the crack tip opening angle is plotted against crack extension in Fig. 14. For large amounts of crack growth, the crack opening angle appears to be approaching a constant value. A more stable parameter appears to be the slope of the crack tip opening displacement versus crack extension curve (Fig. 15). For large amounts of crack growth, the curve becomes extremely linear. Even in the short growth range, the linearity is reasonable. Unfortunately, any crack opening parameters are quite sensitive to the choice of definition. It is impossible to obtain an unambiguous and specimen independent definition. Employment of these criteria, therefore, is limited to a modeling role and should only be employed until a valid, field variable based, local crack extension criterion is established.

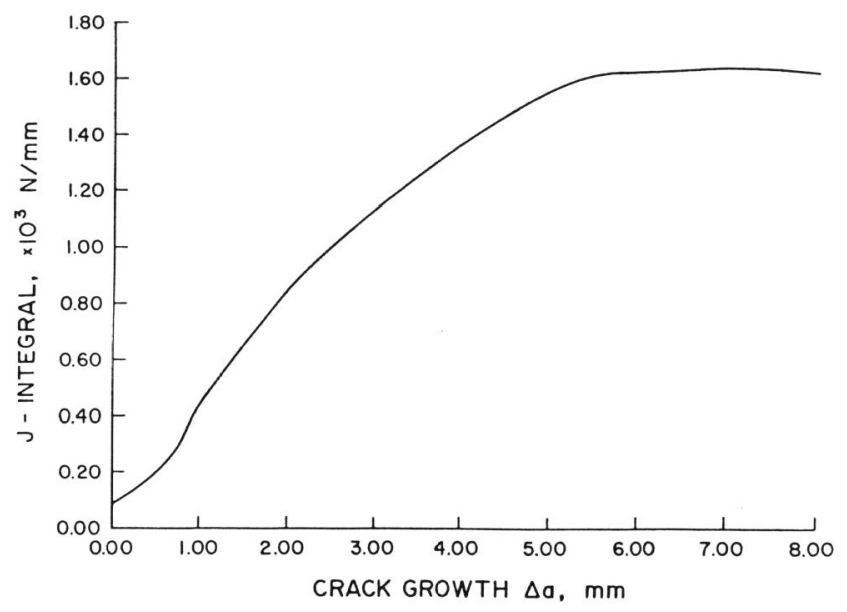

Fig. 13. J-integral vs crack growth

Similar trends can be seen in the literature regarding rate dependent fracture problems. A wide class of applications involves materials which fracture problems. A wide class of applications involves materials which are rate sensitive. sidely studied rate dependent problem is that of secondary creep (both widely studied rate depen in the transient and steady state conditions). performed historically; how hroblems of interest involy stably crack growth. solid has only recently gained attention in the literature. This is interest. The available studies, however, indicate the same trends as for rate independent materials (e.g. that the asymptotic predictions hold primarily for stationary cracks, and that growing crack asymptotics are not 
ghasived at finlle distances; see Hawk and Bassani, 1986 and Moyer and (ietowil, $19 a\})$
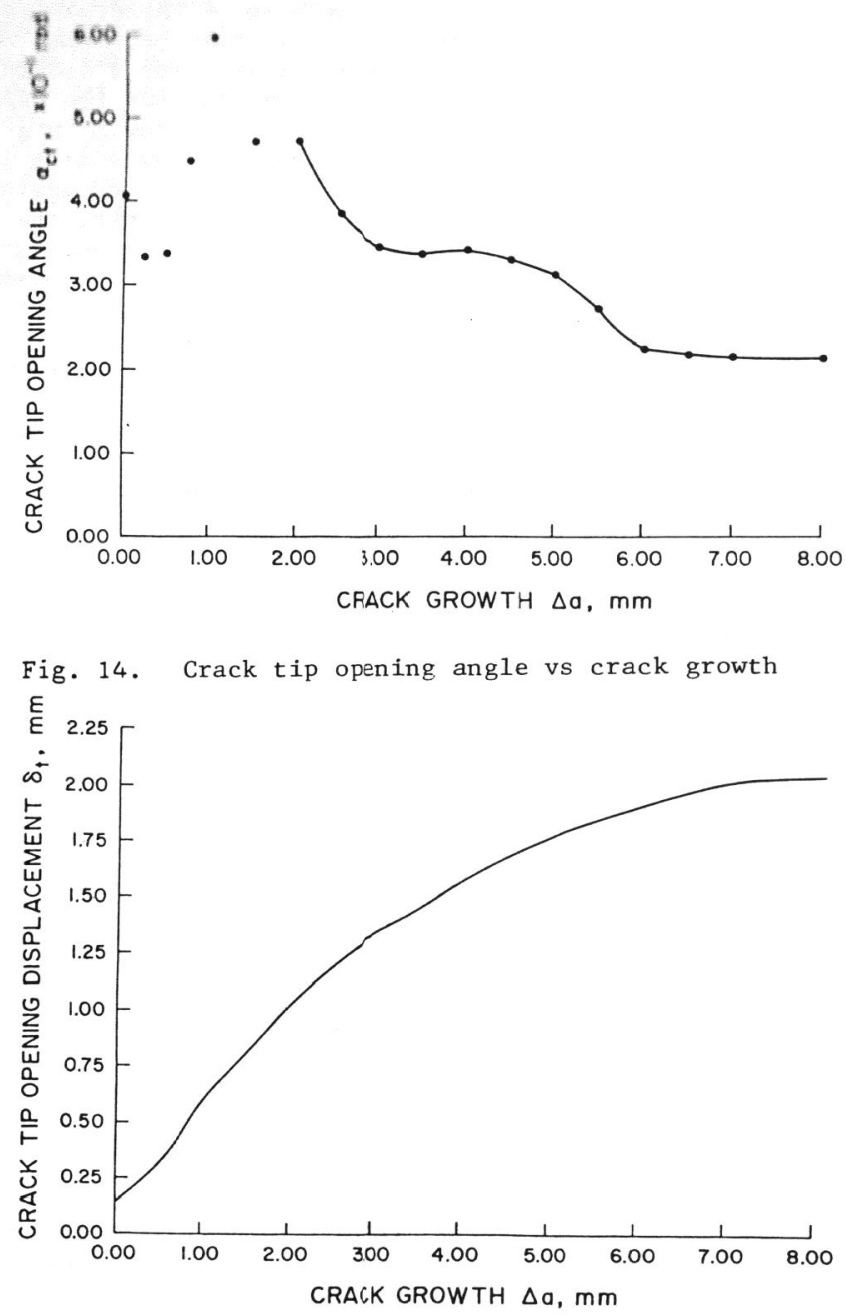

Fig. 15. Crack tip opening displacement vs crack growth

An important aspect of ductile fracture which is starting to receive attention by researchers is the effect of finite deformations on the local crack tip fields. The existence of significant yielding indicates that strain and displacement fields cannot adequately be assumed to be infinitesimal. For both rate independent materials and rate dependent materials, recent research has revealed that finite deformations significantly effect the local stress and strain response of the material (McMeeking, 1987; Moyer and Liebowitz, 1987). Even for a static crack, significant effects can be observed (McMeeking, 1987). Because fracture criteria for stable crack growth will probably involve local field quantities, studying the effects of finite deformation will be imperative. This is even more important for criteria based on local crack opening characteristics. While geometric nonlinearities often increase computational costs, if the local crack region is modeled with a very fine mesh, the large displacement problem may be cheaper to solve as the field may not be singular (as in the infinitesimal theory problems).

An interesting comparison between the asymptotic two dimensional, plane strain fields in the transient, power-law creep problem recently has been studied (Moyer and Liebowitz, 1987). In this problem, the short time solutions were examined while crack opening was still small (so that the asymptotic fields would remain dominant). Figure 16 shows the von Mises stress ahead of the crack tip. The problem was solved numerically using both small and finite strain theory. The problem parameters were chosen so that the transition zone would be negligible and an abrupt transition from the elastic to the creep singular zones would occur. The agreement between the small strain finite element solution and the asymptotic solutions demonstrate this effect. The large deformation solution shows significant differences even for this problem in which deformations are quite small. The elements very near the crack tip experience large enough strains that the entire singular field is influenced. This preliminary study clearly indicates that, as in the elastic-plastic case, finite strain analysis is required to understand ductile and creep fracture problems.

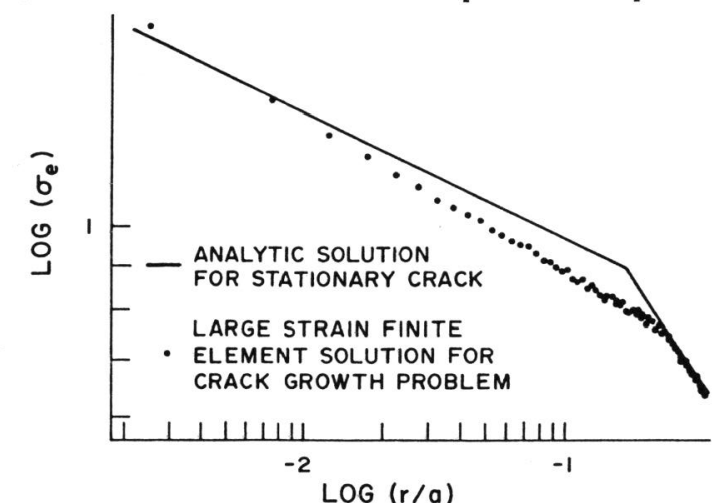

Fig. 16. Log-log plot of asymptotic effective stress ahead of the crack tip after crack growth (P-1500 1b)

Three dimensional ductile fracture studies for stationary cracks are starting to appear in the $1 \mathrm{iterature.} \mathrm{As} \mathrm{mentioned} \mathrm{previously,} \mathrm{the} \mathrm{domain}$ integral approaches are being explored for fracture characterization in th absence of stationary crack growth. The advantage of the domain integral approach is that local solution state need not be accurately represented or predicted. Unfortunately, the local state is the important issue. Current literature is starting to address this problem, however, this work is in its infancy and no conclusions are validated to date.

Numerical solution of ductile crack growth problems provides the opportunity for full field simulation of a complicated physical phenomenon. Laboratory experiments, while extremely important, cannot provide the full field data required to establish a fracture theory to 
predict stable crack growth. Numerical simulation holds great potential ror this use. As discussed subsequently, the need for development of local comput cor reserch

research. FEM solutions should provide the tool to address this research.

SUMMARY OF THE STATE OF KNOWLEDGE NEAR CONTINUUM CRACKS

To fully understand the fracture of solids from a continuum scale, severa pieces of knowledge are required: the field variables must be known near the fracture point (stress, strain, displacement, strain rate, etc.), the thermodnamic laws governing the fracture processes (e.g. stable tearing, ductile rupture, brittle rupture) must be known and the coupling of these must be understood. The theoretical models of the constitutive and fracture behavior of materials must be postulated, understood and verified for real materials. Numerical methods can aid in this process by obtaining solutions to mathematical problems which cannot be solved in closed form; however, numerical solutions cannot provide any information as to the accuracy or validity of postulated theoretical models.

In two dimensions, the asymptotic nature of the field variables is known for elastic materials, as was discussed previously (Eqs. 4 and 5). These are accurate near the crack tip, and the body geometry influence is described by the stress intensity factor. If the crack is near enough to a geometrical boundary, however, the above relations do not adequately ace applications, it does not represent an important problem. For two dimensional, plane strain fracture, knowledge of the stress intensity state is sufficient to predict the onset of brittle fracture. The failure curve (in stress intensity space) is geometry independent and accurate predictions can be made.

For elastic-plastic materials which do not exhibit stable crack growth prior to ductile instability, the local field parameter response is given in Eq. (8) for a power law hardening material. For other simple constitutive relations, similar expressions can be derived analytically. These solutions are two dimensional (either plane stress or plane strain). The loading must be monotonic and no large strain effects can be present. When all these criteria are met, the asymptotic solutions are valid but only in a very small region near the crack tip. In many applications, they are not valid beyond estimates of the process zone size. The utility of these relations, therefore, is extremely restricted. Under these very restrictive assumptions, the J integral represents the energy release rate for mode I failure and can be employed as a fracture criterion. applications, however, this is a poor approximation.

For stationary ductile cracks, numerical solutions exist which describe the local stress, strain and displacement fields. Small strain solutions have been used to study the transition zone between the highly restrictive ductile asymptotic zone and the elastic asymptotic zone. yield zones are shown in Fig. 17. This work has been done for mode I and mixed mode problems in two dimensions (e.g. Shih, 1974; Moyer and Kunze, 1988; Moyer and Haegele, 1988). The transition zone is the regior which probably characterizes the local state most accurately and is region fracture criteria must address. To us fracture criteria for two dimensional ductile tearing are based on crack opening profiles or strain energy density arguments (e.g. Moyer and
Haegele, 1988; Sih, 1985; K. Hellen, 1984). Crack opening criteria are difficult to employ due the fact that these quantities are difficult to measure or precisely predict in an unambiguous manner. More research in this area must be performed to accurately compare numerical and experimental predictions under controlled growth conditions.

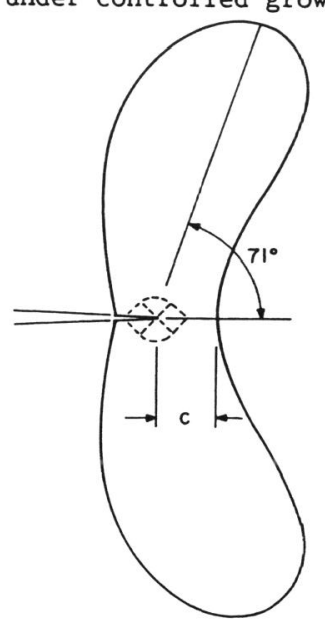

Fig. 17. Shape of the ideal-plastic sma1l-scale yield zone in plane strain, mode I.

Strain energy density approaches for the prediction of ductile crack growth have been proposed for many years. While a large body of literature has grown in this area, little in the way of experimental verification exists. The primary reasons are that the material properties in the formulation are difficult to obtain and the approach is highly sensitive to constitutive and large strain assumptions ( $\mathrm{Sih}, 1985)$. Recent work seems to indicate that ductile tearing is an essentially three dimensional process and that two dimensional approaches (such as crack opening profiles) may not be able to predict ductile fracture. Strain energy density approaches are attractive because they address the problem of element fracture without unnecessary assumptions concerning global response. Much more work in comparing predictions with experiments is required to establish or nullify the approach.

A third local approach to predicting fracture employs continuum damage theory. A constitutive model of a postulated damage parameter is proposed as a function of local stress, strain, strain rate and deformation. A typical damage evolution equation can be given in the form

$$
\dot{D}=f(\underset{\sim}{\sigma}, \underset{\sim}{\varepsilon}, \underset{\sim}{\dot{\varepsilon}}, D)
$$

where $D$ is the damage parameter. The equation is integrated over the loading history and the damage law predicts the material failure dynamically. This approach is being widely researched in Europe and appears promising (Chaboche, 1987; Benallal et al., 1987). Unfortunately, conting The most common approach to addressing ductile fracture in the United
States is through the use of global integrals. The $J$ integral was the 
firt to be employed for fracture resistance characterization in the duetile reaton. Unfortunately, the predictions are far from observed malorial response unless the loading is very near the brittle range. Crack growth and ductile rupture cannot be predicted accurately. Alternative integrals have been proposed which address the restrictions of the $\mathrm{J}$ integral to some degree. Unfortunately, none of these address the material failure or load history problem. In addition, the global integral approaches require unrealistic proportionality assumptions which are not valid for ductile tearing. In spite of the lack of success, much research is focused in this area. It is interesting that research on global integral approaches to address ductile rupture has been largely abandoned except in the U.S.

The problem of fracture at elevated temperatures is very similar to the problem of ductile tearing. Many similarities between viscoplastic and elasto-plastic fracture can be observed in fracture data. For extremely restrictive constitutive models, static crack asymptotic solutions analogous to equation (8) can be established. For example, for steady state power-law creep, the stress and strain rate fields are given by (Reidel and Rice, 1980)

$$
\begin{aligned}
& \sigma_{i j}=\left[\frac{C(t)}{B I_{n} r}\right]^{1 / n+1} \tilde{\sigma}_{i j}(\theta) \\
& \dot{\varepsilon}_{i j}=\left[\frac{C(t)}{B I_{n} r}\right]^{n / n+1}{ }_{\varepsilon}^{\varepsilon}{ }_{i j}(\theta)
\end{aligned}
$$

where

$$
C(t)=\operatorname{Lim}_{\Gamma \rightarrow 0} \int_{\Gamma}\left(\frac{n}{n+1}\right) \sigma_{i j} \dot{\varepsilon}_{i j} d x_{2}-\sigma_{i j} n_{j} \frac{\partial \dot{u}_{i}}{\partial x_{1}} d s .
$$

Unfortunately, creep fracture always exhibits stable crack growth prior to catastrophic failure. These solutions, therefore, have little utility. Early work in creep fracture attempted to employ global integrals to the problem of predicting creep crack growth. As with the $J$ approach in ductile failure, global integrals were not successful. Little additional work has appeared in the 1 iterature with the exception of some recent continuum damage predictions (e.g. Walker and Wilson, 1984; Chaboche, 1987). This work is promising but not yet mature. To date, strain energy approaches have not been applied to viscoplastic problems.

For three dimensional brittle geometries, the deformation and stress state near the crack front has the sane asymptotic form as for the two dimensional case. The stress intensity factors vary as a function of position along the crack front. This solution holds except near the intersection of the crack front with a free surface. The dimension of this "boundary layer" region and the nature of the fields in this region have received much attention with little conclusion. Work on this question is ongoing and recent studies -- both analytically (Folias, 1988) and numerically (Cruse, 1987) -- are beginning to provide qualitative insight. Resolution of this problem is still pending.
Prediction of brittle failure in three dimensions is accomplished using pointwise energy release rate predictions. This approach works well for many practical problems provided the crack extension is planar (as is the case of pure mode I, II or III or for combined modes I and III). For noncoplanar fracture problems, however, the issue remains open. Further non fracture.

For ductile problems, as indicated previously, the prediction of fracture for all problems. This could explain may be inherently three dimensional for alches in the literature. The the lack of success of the dimensional ductile crack front deformation and stress state near a three dimensional ducticu co is just now being studied. Due to the difficult nature of three adress dimensional nonlinear problems, litte an computers are becoming more this problem. Because large, high speed computers are becoming more available, three dimensional ductile fracture problems are being addressed by many researchers. Preliminary results (e.g. Parks and Wang, 1988 ; Moyer et al., 1986) indicate that two dimsional asymtotics do not dain effects near crack region in three dimensions. As suspected, large strain effects appear important and must be modeled. The problen appears very conplicated.

Dynamic fracture phenomena (where inertia effects are important) constitute an important problem in many applications. The two dimensional brittle fracture problem is well understood for the dynamic case. The dynam stress intensity factor represents a valid fracture criterion in this regime. The asymptotic deformation and stress fields have the same form in the static case except that the stress intensity factor becones tine

dependent. For example, a mode I crack running with speed $\mathrm{V}$
asymptotic stress field given by (Williams and Knauss, 1985)

$$
\sigma_{\alpha \beta}=\frac{K(t, v)}{\sqrt{2 \pi r}} f_{\alpha \beta}(\theta, v)+0(1) \quad \alpha, \beta=1,2 \text { as } \quad r \rightarrow 0
$$

where $r$ and $\theta$ are the polar coordinates centered at the crack tip. Material fracture resistance is well understood for brittle dynamic fracture. In three dimensions, crack front energy release rate is analogous to the static problem. Limited
indicates that this approach is promising.

Dynamic ductile fracture has received some study; however, 1 ittle progress has been made in the prediction of fracture phenomena. No asymptotics exist for this problem and 1 ittle is known about the nature of the deformation response. Numerical studies have simulated experiments reasonably well, although no fracture prediction methodology has resulted. The fields near the crack have not been studied adequately. Some thre dimensional work exists; however, this work has focused on global, qualitative comparisons. A recent study focused on determination of the region where the HRR field given by (Parks and Wang, 1988)

$$
\begin{aligned}
& \sigma_{i j}(r, 0) \rightarrow \sigma_{0} \cdot\left[J /\left(\alpha \varepsilon_{0} \sigma_{0} I_{n} r\right)\right]^{\frac{1}{n+1}} \cdot \tilde{\sigma}_{i j}(0, n) \equiv \sigma_{i j}^{H R R} \\
& \varepsilon_{i j}(r, 0) \rightarrow \alpha \varepsilon_{0} \cdot\left[J /\left(\alpha \varepsilon_{0} \sigma_{0} I_{n} r\right)\right]^{\frac{n}{n+1}} \cdot \tilde{\varepsilon}_{i j}(0, n) \equiv \varepsilon_{i j}^{H R R} .
\end{aligned}
$$


This study demonstrated little dominance when the plastic zone was not negligible relative to the crack dimensions. The field of three

dimensional, dynamic ductile fracture is a new frontier.

In general, asymptotic relationships, where applicable, characterize fracture fields and provide the necessary fundamental understanding. When their applicability breaks down, however, little understanding exists. As an example, the problem of two or more interacting cracks demonstrates this. As long as the crack distance separation is large enough, the asymptotic solution is sufficient and the stress intensity factors relat the interaction information ( $\mathrm{Sih}, 1978$ ). If they are too factors relate the fields are unknown. Little work in this area (either exe, however, numerical or analytical) has been performed. In light in micromechanical modeling of fracture processes (e.g. void nucleation, void coalescence, crack-void interaction) this is an imortant issuen, warrants further research. At the moment, no uniform determining the extent or validity of asymptotic solutions for

asymptotic behavior of the acyicture regimes are summarized in Table 3 .

Table 3. Near crack field singularities

\begin{tabular}{|c|c|c|c|c|}
\hline Problem type & Stress & Strain & Energy & Comments \\
\hline 2-D Elastic & $1 / \sqrt{\mathrm{r}}$ & $1 / \sqrt{r}$ & $1 / r$ & $\begin{array}{l}\text { Exact asymptotic } \\
\text { solution }\end{array}$ \\
\hline 3-D Elastic & $1 / \sqrt{r}$ & $1 / \sqrt{\mathrm{r}}$ & $1 / r$ & $\begin{array}{l}\text { Restricted to interior } \\
\text { domain }\end{array}$ \\
\hline $\begin{array}{l}2-D \text { Nonl inear } \\
\text { Elastic }\end{array}$ & $\mathrm{r}^{-1 / n+1}$ & $r^{-n / n+1}$ & $1 / r$ & $\begin{array}{l}\text { Applicable region very } \\
\text { small - limited plastic } \\
\text { and constitutive behavior } \\
\text { limited to monotonic load }\end{array}$ \\
\hline 2-D Creep & $\mathrm{r}^{-1 / \mathrm{n}+1}$ & $\mathrm{r}^{-\mathrm{n} / \mathrm{n}+1}$ & $1 / r$ & $\begin{array}{l}\text { Applicable region very sm } \\
\text { limited creep size and } \\
\text { constitutive behavior - } \\
\text { limited to monotonic load }\end{array}$ \\
\hline 3-D Nonl inear & $? ? ?$ & $? ? ?$ & ??? & $\begin{array}{l}\text { Unsolved to date elastic } \\
\text { analytically - numerical } \\
\text { solutions forthcoming }\end{array}$ \\
\hline $\begin{array}{l}\text { 2-D Plastic } \\
\text { with Local } \\
\text { Unloading }\end{array}$ & $? ? ?$ & ??? & ??? & $\begin{array}{l}\text { Unsolved to date } \\
\text { analytically - numerical } \\
\text { solutions forthcoming }\end{array}$ \\
\hline $\begin{array}{l}3-D \text { Plastic } \\
\text { vith Local } \\
\text { Jnloading }\end{array}$ & ??? & $? ? ?$ & $? ? ?$ & $\begin{array}{l}\text { Unsolved to date } \\
\text { analytically - numerical } \\
\text { solutions forthcoming }\end{array}$ \\
\hline
\end{tabular}

APPLICATION OF FRACTURE MECHANICS

Fracture mechanics has found a wide variety of applications over the years. The design of aircraft structures, aerospace structures, submarines, ships, land vehicles and civil structures employ fracture mechanics based rules in the design code standards. An excellent review of this topic can be found in Hellen (1987). For emerging disciplines, the characterization of fracture resistance (or fracture toughness) is a demanding and challenging extension of the technology.

From a fracture mechanics standpoint, the field of composite materials has many open questions with regard to theoretical issues. Numerically, however, linear elastic composite problems can be solved quite accurately using FEM or BIEM, albeit, often at great computational expense. The field of theoretical basis for composites needs to be greatly expanded before the numerical needs can be established. For the time being, the problems of interface cracks, free surface cracks and laminate interface modeling will occupy much numerical research effort. These problems are soluble with current technology; however, much effort will be required.

An important problem area where fracture mechanics finds application is in the prediction of fatigue crack growth rates and fatigue 1 ife. A full discussion of the problem of, fatigue is beyond the scope of this paper. It is important to note, however, that while fracture mechanics approaches to fatigue crack propagation have been used for twenty-five years, only problems involving relatively long cracks in long-life (high-cycle fatigue) materials can be adequately addressed with these approaches. Work is ongoing and promising in this area, especially approaches based on local energy criteria. Unfortunately, the level of effort on this problem is not commensurate with its importance. More effort and funding are required in this important area as the majority of real world failures and component retirements are due to fatigue.

An area in which fracture mechanics technology is currently being tested for applicability is the simulation of metal cutting. For the prediction of tool wear, safe cutting speeds, optimal cutting depths, etc. it is desirable to have a predictive technology to determine the stress and strain fields arising from the process. While work in this area is complicated due to dynamic, thermal and strain rate effects, promising research is underway. Examples of this work can be found in Strenkowski and Carroll (1985).

Fracture mechanics has been successfully applied to the failure characterization of ceramic materials for many years. An excellent review of the fracture of ceramic materials can be found in Bradt et al. (1974). Ceramics often exhibit viscoelastic and anisotropic material behavior complicating their analysis; however, because they tend to be brittle, energy release rate predictions tend to characterize fracture quite well.

An area of active research in mechanics and material science is in the processing and performance characterization of thin film coatings. Coating base materials can provide increased strength and tribological properties for engineering components. The coated material often has superior performance capabilities to the base material alone. Fracture characterization of thin film coatings is receiving attention by researchers. Several approaches to fracture characterization have been proposed and are under study. Promising results indicate that methodology 


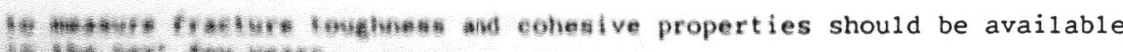
it the thent fow yests

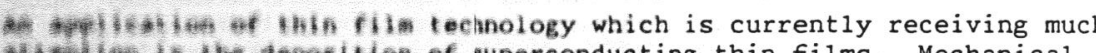
*1tatifer it the depestition of superconducting thin films. Mechanica tharmientiation of superconducting thin films is complicated by the Iswersture sensitivity and anisotropy of these materials. Technology developed for characterizing room temperature thin films should be ext wintole to liquid nitrogen environments. Orthotropy in the coatings mechanical properties, however, is an issue requiring further research.

Recent research on thin film technology has led to the development of nanostructured thin films. Typically these coatings are constructed of two materials alternately layered. The total coating may consist of as many as 500 layer pairs with layer thickness on the order of 10 angstroms. Different layer thicknesses and volume ratios produce varied material properties. The nanostructuring of these coatings often yield mechanical properties superior to those of a single material of equivalent coating thickness. Research is ongoing to determine optimal layer spacing and proportions for fracture resistance, tribological properties and strength. Current research indicates that single coating film techniques for fracture for the characterization of nanostructured thin films (Moyer et al., 1988).

Application of fracture mechanics principles and extension of the theory to emerging material technologies is one of the most challenging tasks for the field. Due to the complexity of the arising applications, computational approaches increasingly will be employed. Vigorous research is needed in these areas. Preliminary indications are that fracture mechanics wil provide a framework for the characterization of many of these emerging applications.

FRACTURE MECHANICS RESEARCH NEEDS AND THE ROLE OF NUMERICAL ANALYSIS

Research needs in fracture mechanics are quite varied and still pose formidable tasks for engineers and scientists. The failure of isotropic, brittle materials is well understood today. Existence fracture theories for mode I failure are well established in two and three dimensions. Existing FEM and BIEM technology can routinely solve LEFM problems with the exception of the problems of interface crack and the intersection of a crack with a free surface. These problems require further study, al though current research seems to be converging on an understanding of these phenomena.

LEFM problems involving mixed mode fracture have been less precisely theorized. Sufficient theoretical framework exists; however, it has not been tested adequately. Interest in mixed mode fracture of metals historically has been given less importance than warranted by the existence of mixed mode failures. This imbalance needs to be addressed if LEFM is to become a truly mature technology. Current numerical methods for two-dimensional mixed mode LEFM problems are adequate. Three dimensional problems can be solved; however, methods for extraction of relative racture parameters (e.g. stress intensity factors or energy release rates) are not quite mature. When the appropriate parameters are theoretically established, existing numerical techniques can be evaluated. (In fact, such evaluations are ongoing as interest in three-dimensional composit problems increases). Completing the development of numerical techniques for LEFM problems should be easily accomplished in the next several years.

The problems involving material nonlinearities constitute the greater challenge for both numerical analysts and fracture theorists. The need for a richer fracture theory which can predict the onset and propagation of a stable crack is by far the greatest research need. Such a theory, by the very local nature of the deformation and the complication of simultaneous loading and unloading of the material, will require local fracture theory in the neighborhood of the crack. From a purely continuum viewpoint, such a criterion must address the local energetics of the crack propagation and incorporate the energy loss due to crack growth, energy loss due to plastic dissipation and energy input from applied loading in a self consistent manner. Several researchers are addressing this issue; unfortunately, the majority of the community is pursuing other, unlikely, avenues.

From a computational perspective, the major needs in support of ductile fracture research are algorithms which can more quickly solve nonlinear problems, better time integration schemes for rate dependent problems and better methods for extracting local crack front field quantities. Nonlinearities occurring due to material behavior and finite deformations must be addressed at the outset in a consistent manner. Specifically, crack growth modeling algorithms must be studied to determine mesh
sensitivity and convergence with respect to near crack front field quantities. To date, these studies are lacking. Of primary interest will be the convergence of stress, strain (or deformation gradient) and energy fields as these are the quantities which must make up a viable local fracture criteria.

An area which has received some recent interest is the problem of shor cracks. While much testing has been performed, little in the way of fundamental understanding has emerged. The propagation characteristics of short cracks and its influence on future instability would appear to be critical question. Microstructure effects are more important for short crack problems and should be included in the theory. More research on developing predictive methodology and a theoretical framework is needed.

The focus of this paper has been on deterministic fracture mechanics. Indeed, where applicable, deterministic methodology for the prediction of fracture is desirable as uncertainty is eliminated. For applications involving random loading or imprecise knowledge of the loading, geometry or material response, deterministic fracture methodology is not applicable. For these applications, stochastic methods are required. Stochastic methods for the prediction of fatigue and fracture have been employed for more than twenty years. These methods can often provide an estimate of safety and life prediction for problems which are otherwise not addressable. Because stochastic approaches employ random variables to represent physical parameters, extreme care must be exercised to validate the model and the data before application. Validation methodology and assessment of accuracy of these techniques require considerable research before routine application can be safely accomplished.

In the short term, the FEM must provide the solution methodology and improved algorithms desired, as it is the most firmly established and robust methodology for nonl inear problems. The open questions discussed above must be attacked from a purely numerical (mathematical) approach to establish accurate results to the posed problems. These solutions, 
therefore, will establish the validity (or lack thereof) of the assumptions . A much more concentrated, broader

concurrent with FEM research, the BIEM method should be studied. This must nonlinear problems. Howe investment as the method is not ideally suited to removed (iscretization is dimensional mesh while $B$ IFM requires a two is extremely attractive. only produces a BIEM for nonl inear problems may improve solutions: namely the low resolution

An important issue is the application of fracture mechanics to real problems. It is necessary to take methodology from the 1 aboratory and the aspect of interion to obtain a full assessment. This analysis world strong cooperative,

A discipline which may assist in the integration of fracture mechanics to expert systems. integrated exp. It may be possible to create design systems with an process. While knowledge base and a hierarchical, rule based decision yet to be explored, disciplines inded, the success of knowledge based systems in other mechanics mechanics information should be attempted.

Another issue which needs concentrated effort is development of high-risk, long-term issues which may or may not directly influence curren

responsens. Unanswered questions in the real nature of local deformation present, where present, where crack tip blunting exists, where thermal gradients are problems expe field. Because these mathematics, more rotics, numerical approaches must be employed. More refined modeling, required. required. Going into such investigations, the payoffs will be totally resear. however, willis area is almost nonexistent. Future breakthroughs, understo understood. Research on these issues, therefore, is essential.

The National Agency for Finite Element Methods and Standards (NAFEMS) has 列 safor engineering structures and in a variety In industries. They form an integral part of the design/redesign cycle. In the U.K., the National Engineering Laboratory has brought together leading users of finite element nethods to form the National Agency for Finite Element Methods and Standards, which has as its objective the aim of producing tests which can easily result in performance figures which will then be useful for potential users of commercial finite element codes. benchmarks themselve have tried to aim for known or likely weaknesses in ommercial systems.

The NAFEMS Fracture Mechanics Working Group under the chairmanship of $\mathrm{Dr}$.
Trevor K. Hellen is working on benchmark tests applicable to the fracture of structures. The forthcoming results should be important for the users of the various codes being utilized today in fracture mechanics. Such studies should be encouraged.

While much progress has been made in the solution of the complicated problems in fracture mechanics over the years, it should be obvious to the reader that fracture mechanics is far from a mature discipline. The issues summarized above (in addition to many other topics beyond the scope of this paper) warrant a significant research effort far beyond the current level. Major advances can only be made through a large, international, cooperative effort which is well supported by both government and industry. Fracture mechanics historically has enjoyed a great degree of international cooperation. This is to be congratulated and encouraged.

\section{ACKNOWLEDGMENT}

The author acknowledges with deep appreciation the significant contributions made by Dr. E. Thomas Moyer Jr. during the preparation of this paper. His efforts have greatly enhanced the quality and comprehensiveness of this presentation.

\section{REFERENCES}

Anderson, J.M. and King, w.w. (1977). In: ASTM STP No. 627, ASTM, Philadelphia.

Atluri, S.N. and Kathisesan, K. (1980). Int. J. Pressure Vessel Tech. $\underline{102}, 278$.

Baner jee, P.K. and Butterfield, R. (1981). Boundary Elements in Engineering Science. McGraw Hill, New Jersey.

Barsoum, R.S. (1976). Int. J. Num. Meth. Eng., 10, 25.

BEASY. Structural Analysis Corporation, Swansea, U.K.

Benallal, A., Bilardon, R., Doghri, I. and Moret-Bailly, L. (1987). In: Numerical Methods in Fracture Mechanics, Proceedings of the Fourth

International Conference (A.R. Luxmore, D.R.J. Owen, Y.P.S. Rajupakse and M.F. Kannien, eds.). Pineridge Press.

Blackburn, W.S. and Hellen, T.K. (1979). Int. J. Num. Meth. Eng., 11, 211. Bradt, R.C., Hasselman, D.P.H. and Lange, F.F., Eds. (1974). Fracture Mechanics of Ceramics. Plenum Press, New York.

Chaboche, J.L. (1987). In: Numerical Methods in Fracture Mechanics,

Proceedings of the Fourth International Conference (A.R. Luxmore, D.R.J. Owen, Y.P.S. Rajupakse and M.F. Kannien, eds.). Pineridge Press.

Cruse, T. (1987). In: Numerical Methods in Fracture Mechanics,

Proceedings of the Fourth International Conference (A.R. Luxmore, D.R.J. Owen, Y.P.S. Rajupakse and M.F. Kannien, eds.). Pineridge Press.

Dean, R.H and Hutchinson, J.W. (1980). ASTM STP No. 700, ASTM, Philadelphia.

Dexter, R. (1987). In: Numerical Methods in Fracture Mechanics, Proceedings of the Fourth International Conference (A.R. Luxmore, D.R.J. Owen, Y.P.S. Rajupakse and M.F. Kannien, eds.). Pineridge Press.

Dodds, R.H. Jr. and Read, D.T. (1988). In: Analytical, Numerical and Experimental Aspects of Three Dimensional Fracture Processes (A.J. . ASME AMD Vol. 91.

Folias, E. (1988). In: Analytical, Numerical and Experimental Aspects of Three Dimensional Fracture Processes (A.J. Rosakis, K. Ravi-Chandar and Y. Rajapakse, eds.), ASME AMD Vol. 91. 
Hawk, D.E. and Bassani, J.L. (1986). J. Mech. and Phys. Solids, 34, 191. Hellen, K. (1984). Introduction to Fracture Mechanics. McGraw Hili, New York.

Hellen, T.K. (1987). In: Numerical Methods in Fracture Mechanics, Proceedings of the Fourth International Conference (A.R. Luxmore, D.R.J. Owen, Y.P.S. Rajupakse and M.F. Kannien, eds.). Pineridge Press. Henshell, R.D. and Shaw, K.G. (1975). Int. J. Num. Meth. Eng., 9, 496. Hilton, P.D. (1977). In Plates and Shells With Cracks (G.C. Sih, ed.), Noordhoff, The Netherlands.

Hoff, R., Rubin, C.A. and Hahn, G.T. (1986). J. Eng. Frac. Mech., 23, 105. Ingraffea, A.R. and Manu, C. (1980). Int. J. Num. Meth. Eng., 15, 1427. Kuna, M. (1982). Int. J. Frac., 19, R62.

Lapidus, L. and Pinder, G.F. (1982). Numerical Solution of Partial Differential Equations in Science and Engineering. John Wiley and Sons, New York.

Liebowitz, H. and Moyer Jr., E.T. (1987). Proc. of the Conference on Finite Element Methods in Engineering, Melbourne, Australia. To appear in a special issue of Eng. Frac. Mech.

McMeeking, R.M. (1987). In: Numerical Methods in Fracture Mechanics, Proceedings of the Fourth International Conference (A.R. Luxmore, D.R.J. Owen, Y.P.S. Rajupakse and M.F. Kannien, eds.). Pineridge Press.

Moyer, E.T. Jr. (1988). In: Fracture Mechanics: The Nineteenth Symposium (T. Cruse, ed.), ASTM STP 969.

Moyer, E.T. Jr., Kramer, B. and Yang, S.H. (1988). Joint ASME/SES Applied Mechanics and Engineering Sciences Conference, Berkeley, California.

Moyer, E.T. Jr., Poulose, P.K. and Liebowitz H. (1986). J. Eng. Frac. Mech., 24, 677

Moyer, E.T. Jr. and Haegele, M. (1988). Ductile Mixed Mode Fracture Fields, and Failure Prediction. (To appear).

Moyer, E.T. Jr. and Kunze, K. (1988). Stress, Strain and Deformation Fields Near a Growing Crack. (To appear).

Moyer, E.T. Jr. and Liebowitz, H. (1984). Proc. 21st Annual Mtg. of the Society for Engineering, Blacksburg, Virginia.

Moyer, E.T. Jr. and Liebowitz, H. (1987). J. Eng. Frac. Mech., 28,601

Muskhelishvili, N.I. (1953). Sirgular Integral Equations. Noordhoff Press, The Netherlands.

Newman, J.C. Jr. (1988). Int. J, Frac., (forthcoming).

Parks, D.M., (1974). Int. J. Frac., 10, 487

Parks, D.M. and Wang, Y.Y. (1988). In: Analytical, Numerical and Experimental Aspects of Three Dimensional Fracture Processes (A. Rosakis, K. Ravi-Chandar and Y. Rajapakse, eds, ), ASME AMD Vol.J.

Raju, I.S. and Newman, J.C. Jr. (1977). NASA TM X-73825.

Reidel, H. and Rice, J.R. (1980), ASTM STP No. 700, ASTM, Philadelphia.

Rice, J.R. (1968). In Fracture (H. Liebowitz, ed.), Vol. 2, Academic

Press, New York.

Rooke, D.P., Cartwright, D.J. and Aliabadi, M.H. (1987). In: Numerical Methods in Fracture Mechanics, Proceedings of the Fourth International Conference (A.R. Luxmore, D.R.J. Owen, Y.P.S. Rajupakse and M.F. Kannien, eds.). Pineridge Press.

Shih, C.F. (1974). In ASTM STP No. 560, ASTM, Philadelphia.

Shih, C.F., Moran B. and Nakamura T. (1988). In: Analytical, Numerical and Experimental Aspects of Three Dimensional Fracture Processes (A.J. Rosakis, K. Ravi-Chandar and Y. Rajapakse, eds.), ASME AMD Vol. 91.

Sih, G.C. (1978). Handbook of Stress Intensity Factors. Lehigh University Press, Bethlehem, Pennsylvania.

Sih, G.C. (1985). In: Fracture Mechanics Technology Applied to Material Evaluation and Structure Design (G.C. Sih, N.E. Ryan and R. Jones, eds.), Martinus Nijhoff Publishers.
Strenkowski, J.S. and Carrol1, J.T. III (1985). J. Eng. for Industry, 107, 349 .

Swenson, D. and Ingraffea, A. (1987). In: Numerical Methods in Fracture Mechanics, Proceedings of the Fourth International Conference, (A.R Luxmore, D.R.J. Owen, Y.P.s. Rin Pineridge Press.

Tracey, D.M. (1973). Int. J. Frac., 9, 340

Walker, K.P. and Wilson, D.A. (1984). AFWAL-TR-84-4073, Wright Patterson Air Force Base, Dayton, Ohio.

Williams, M.L. and Knauss, W.G., Eds. (1985). Dynamic Fracture. Martinus

Ni jhoff Publishers.
Wilson, R.B., Bak, M.F., Nakazawa, S. and Banerjee, P.K. (1985). NASA Contract Report, MAS3-23697, National Aeronautics and Space Administration, Washington, D.C. 